\title{
Profit Maximization, Industry Structure, and Competition: A critique of neoclassical theory
}

\author{
Steve Keen (University of Western Sydney) \\ Russell Standish (University of New South Wales) \\ Locked Bag 1797, Penrith 1797, Australia.s.keen@uws.edu.au
}

\begin{abstract}
Neoclassical economics has two theories of competition between profit-maximizing firms (Marshallian and Cournot-Nash) that start from different premises about the degree of strategic interaction between firms, yet reach the same result, that market price falls as the number of firms in an industry increases. The Marshallian argument is strictly false. We integrate the different premises, and establish that the optimal level of strategic interaction between competing firms is zero. Simulations support our analysis and reveal intriguing emergent behaviors.
\end{abstract}

PACS Code: 89.65.Gh

Key words: Microeconomics, Profit Maximization, Competition, Monopoly, Oligopoly, Cournot-Nash Game Theory

\section{A popular fallacy}

The underlying assumption of the Marshallian model is that the $i^{t h}$ firm in a competitive industry does not react strategically to the hypothetical actions of other firms. In an $n$ firm industry where the output of the $i^{\text {th }}$ firm is $q_{i}$, this assumption, known as "atomism" or "price-taking",[1, pp. 314, 383] means that $\frac{\partial q_{i}}{\partial q_{j}}=0 \forall i \neq j$. This model then claims that the market demand function $P(Q)$ (where $Q=\sum_{i=1}^{n} q_{i}$ ) has the dual properties that $P^{\prime}(Q)<0$ and $P^{\prime}\left(q_{i}\right)=$ 0 for large $n$. Elementary calculus shows this is false:

$$
\frac{d P}{d q_{i}}=\frac{d P}{d Q} \frac{d Q}{d q_{i}}
$$


where $\frac{d Q}{d q_{i}}=1$ given $\frac{\partial q_{i}}{\partial q_{j}}=0 \forall i \neq j$. Therefore $\frac{d P}{d q_{i}}=\frac{d P}{d Q}([2])$.

This false belief is essential to the Marshallian derivation of the model of "perfect competition", which occurs when $P(Q)$ - the marginal benefit to societyequals the marginal cost of production $M C(Q) \cdot[1$, p. 322] The derivation starts from the proposition that a profit maximizing firm will produce where its Marginal Cost $\left(\frac{d}{d q_{i}} T C\left(q_{i}\right)\right)$ equals its Marginal Revenue $\left(\frac{d}{d q_{i}}\left(P(Q) q_{i}\right)\right)$ :

$$
\pi_{\text {neo }}: \frac{d}{d q_{i}} \pi\left(q_{i}\right)=M R\left(q_{i}\right)-M C\left(q_{i}\right)=0
$$

Given this alleged profit-maximization rule and the "assumption" that $P^{\prime}\left(q_{i}\right)=$ 0 , it followed that for perfect competition, price equalled marginal cost. Since the assumption is logically incompatible with $P^{\prime}(Q)<0$, the Marshallian derivation of perfect competition fails.

The Cournot-Nash model is not dependent on this fallacy, arguing instead that strategic interactions lead to a Nash equilibrium in which market price converges to marginal cost as the number of firms increases ([3]; [1, pp. 411413.]) - though this process is, at best, highly conditional at best (see [1, pp. 417-423]). Standard neoclassical analysis assumes that firms will strategically interact, and calculates the $i^{t h}$ firm's best response on this basis under various conditions. We instead treat $\frac{\partial q_{i}}{\partial q_{j}}$, the response of the $i^{t h}$ firm to a hypothetical change in output by the $j^{\text {th }}$, as a decision variable, and consider what is its

optimal value of $\frac{\partial q_{i}}{\partial q_{j}}$ for a profit-maximizing firm. As a preliminary, we show that the proposition that (2) maximizes profits for the $i^{\text {th }}$ firm is false.

\section{The true profit maximization formula}

In a multi-firm industry, the profit maximum is given by the zero, not of its partial derivative, but its total derivative - since the actions of other firms affect the profitability of any given firm, even though (or rather, especially because) the $i^{\text {th }}$ firm cannot control what the other firms in the industry do. Maximizing profit while ignoring what other firms do is rather like rowing a boat to a specific location while ignoring the wind and tides. The profit maximum for the $i^{\text {th }}$ firm is therefore given by:

$$
\frac{d}{d Q} \pi\left(q_{i}\right)=\frac{d}{d Q}\left(P(Q) q_{i}-T C\left(q_{i}\right)\right)=0
$$


Since $Q=\sum_{j=1}^{n} q_{j},(3)$ can be expanded to

$$
\sum_{j=1}^{n}\left(\frac{\partial}{\partial q_{j}}\left(P\left(\sum_{j=1}^{n} q_{j}\right) q_{i}-T C\left(q_{i}\right)\right) \frac{d q_{j}}{d Q}\right)=0
$$

Converting (4) into an expression in terms of reaction coefficients $\frac{\partial q_{i}}{\partial q_{j}}$ yields:

$$
P \sum_{j=1}^{n}\left(\frac{\partial q_{i}}{\partial q_{j}} \sum_{k=1}^{n} \frac{\partial q_{j}}{\partial q_{k}}\right)+q_{i} \frac{d P}{d Q} \sum_{j=1}^{n} \sum_{k=1}^{n} \frac{\partial q_{j}}{\partial q_{k}}-M C\left(q_{i}\right) \sum_{j=1}^{n} \frac{\partial q_{i}}{\partial q_{j}}=0
$$

With the Marshallian assumption of "atomism", $\frac{\partial q_{i}}{\partial q_{j}}=0 \forall i \neq j$, and equation (5) reduces to

$$
P+n q_{i} \frac{d P}{d Q}-M C\left(q_{i}\right)=0
$$

This contradicts the neoclassical belief, epitomized by (2), that, in the context of atomistic behavior, profit is maximized by equating marginal revenue and marginal cost. (6) can be rearranged to yield:

$$
M R\left(q_{i}\right)-M C\left(q_{i}\right)=\frac{n-1}{n}\left(P-M C\left(q_{i}\right)\right)
$$

This equals zero only in the case of a monopoly - which is the one time that the accepted Marshallian formula is correct. At all other times, the profit maximum for an individual firm will occur where "marginal revenue" exceeds "marginal cost". As a consequence, the Marshallian model leads to industry output being independent of the number of firms in it.

In Cournot-Nash game theoretic analysis, firms decide their own actions on the basis of the expected reactions of other firms, in such a way that each firm's "best response" is to set $M R\left(q_{i}\right)=M C\left(q_{i}\right)$. In our terms, this is equivalent to setting $\frac{\partial q_{i}}{\partial q_{j}}=\frac{1}{n E}$-where $\mathrm{E}$ is the market elasticity of demand $\left(E=\frac{P}{Q} \frac{d Q}{d P}\right)$. Our equation (5) lets us combine Marshallian and Cournot-Nash analysis, by treating $\frac{\partial q_{i}}{\partial q_{j}}$ as a decision variable whose optimum value can be identified by the firm. In this paper, we consider an industry of $n$ identical firms (a common heuristic device in economic theory) so that $\frac{\partial q_{i}}{\partial q_{j}}=\theta \forall i \neq j$ and $\frac{\partial q_{i}}{\partial q_{i}}=1$, where 
$\theta$ can take on any value. Then (5) reduces to:

$$
(n-1) P \theta+P+n q_{i} \frac{d P}{d Q}=M C\left(q_{i}\right)
$$

This defines the maximum profit achievable by the individual firm in the context of strategic behavior - if each firm reacts to output changes by other firms with a reaction coefficient of $\theta$. We can now consider what value of $\theta$ would be chosen by a profit-maximizing firm. It transpires that the optimum value of this parameter is in fact zero.

\section{True profit-maximizing behavior}

The optimum value for $\theta$ for the $i^{t h}$ firm occurs where $\frac{d}{d \theta} \pi\left(q_{i}\right)=0$. This condition reduces to:

$$
\frac{d}{d \theta} \pi\left(q_{i}\right)=\frac{1}{n} \frac{d}{d \theta} Q\left(P+n q_{i} \frac{d P}{d Q}-M C\left(q_{i}\right)\right)
$$

Since it can be shown that $\frac{d}{d \theta} Q \neq 0,(9)$ equals zero iff $P+n q_{i} \frac{d P}{d Q}-M C\left(q_{i}\right)=0$. As established above, this requires that $\theta=0$. Firms thus achieve higher profits if they do not react strategically to each other. In the classic words of the movie War Games, firms may conclude that Cournot-Nash strategic interaction is "A curious game. The only winning strategy is not to play." We consider this question using a multi-agent model of instrumentally rational profit maximizers facing comparable marginal cost functions.

\section{Operationally rational profit-maximizers}

Our hypothetical market has a linear demand curve $(P=a-b Q)$ and a given number $n$ of profit-maximizing agents. Firm $i$ chooses an initial output level $q_{i, 0}$ and a fixed amount by which to vary output at each step $\delta q_{i}$. If profit falls after an iteration, $i$ reverses the sign of $\delta q_{i}$ for the next iteration. ${ }^{1}$ Total cost

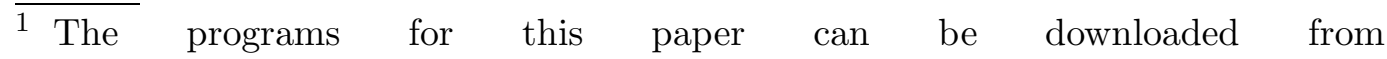
www.debunking-economics.com/totf. 
functions for the firms are identical:

$$
t c(q, n)=k+C q+\frac{1}{2} D n q^{2}+\frac{1}{3} E n^{2} q^{3}
$$

In the following simulations, $a=800$ and $b=10^{-7}, k=10^{6}, C=10$, $D=10^{-8}$ and $E=10^{-17}$ and $n$ ranges between 5 and 100 (higher values made no significant difference to our results.); the fixed $\delta q_{i}$ for each firm is drawn from a normal distribution $N(m, \sigma)$ where $m=0$ and $\sigma$ is a given fraction of the Cournot prediction. Monte Carlo simulations reveal a rich range of interactions, and in general show that instrumentally rational profit-maximizers will learn "not to play" the Cournot-Nash game. For low $\sigma$, output converges to the "Keen" equilibrium given by (6) for all values of $n$ (Figure 1).

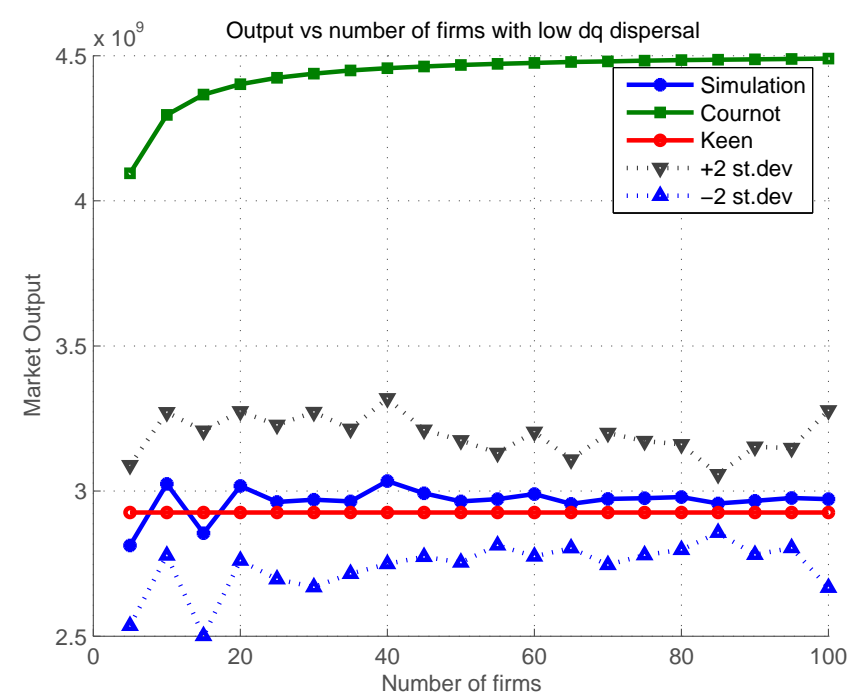

Fig. 1. Outcome of Monte Carlo simulations with low dispersal of $\delta q$ (2\% Cournot)

However, as $\sigma$ rises from $1 \%$ to $20 \%$ of the Cournot prediction, the outcome shifts from the Keen to the Cournot level (Figure 2). Aggregate and individual agent behavior also becomes much more unstable, as Figure 3 indicates. We surmise that the "emergent collusion" we identified in [4] breaks down as $\delta q$ rises; perhaps the increasing size of unpredictable output changes by other firms makes the overall market environment more chaotic, forcing each firm to rely more on feedback from its own output.changes.

\section{Conclusion}

Contrary to the beliefs of the vast majority of economists, equating marginal revenue and marginal cost is not profit-maximizing behavior, the number of 


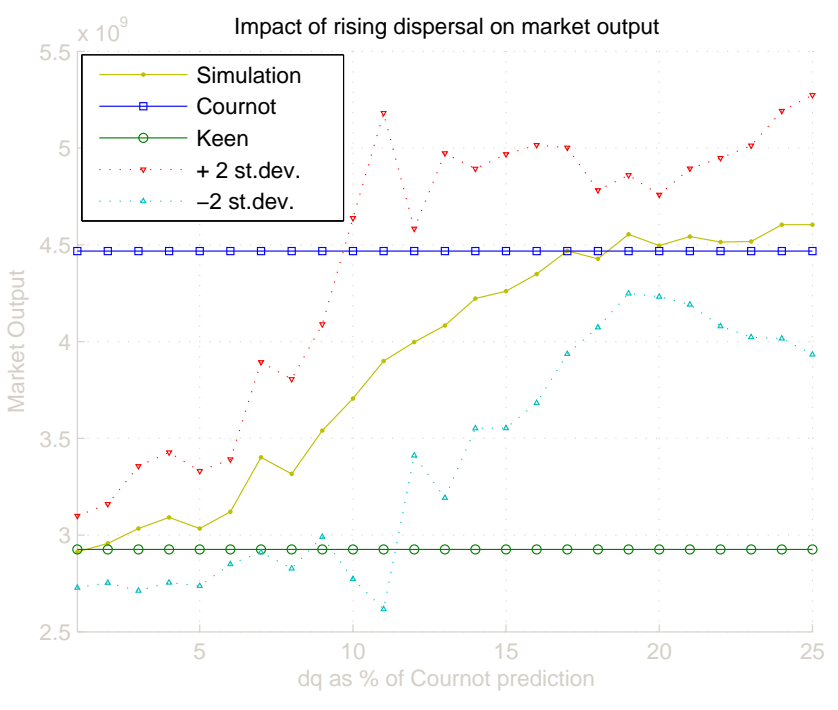

Fig. 2. Convergence to Cournot-Nash prediction as $\delta q$ rises with constant $n=50$

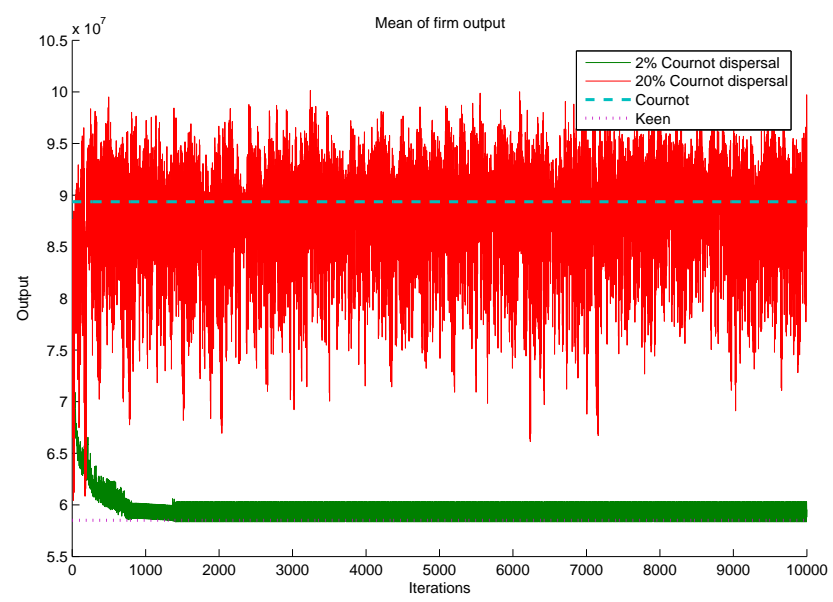

Fig. 3. Comparative stability of average firm for different values of $\delta q$

firms in an industry has no discernible impact on the quantity produced, the "deadweight loss of welfare" exists regardless of how many firms there are in the industry, and instrumentally rational profit-maximizers do not play Cournot-Nash games. Moving from Hollywood to The Bard, it appears that the dominant theory of the firm is "Much Ado About Nothing".

\section{References}

[1] A. Mas-Colell, M.D. Whinston, J.R.Green, Microeconomics, Oxford University Press, New York, (1995).

[2] G. Stigler, Perfect competition, historically contemplated, Journal of Political 
Economy, 65 (1957) 1-19.

[3] F. Vega-Redondo, The evolution of Walrasian behavior, Econometrica, 65 (1997) $375-384$.

[4] R.K. Standish and S. Keen, "Emergent Effective Collusion in an Economy of Perfectly Rational Competitors", Stonier, et al. (eds.), Proceedings 7th AsiaPacific Conference on Complex Systems, Cairns, arXiv:nlin.AO/0411006, (2004), 228 